\title{
Retratos-collages de masculinidades en un contexto penitenciario: Tensiones entre visibilidad e invisibilidad
}

\section{Portraits-collages of masculinities in a penitentiary context: Tensions between visibility and invisibility}

TIPO DE TRABAJO: Poster.

PALABRAS CLAVE

Retrato-Collages, Identidad, Subjetividad, Narrativa, Hegemonía.

KEY WORDS

Portrait-Collages, Identity, Subjectivity, Narrative, Hegemony.

RESUMEN

El presente póster da cuenta del proceso y alcances de una indagación que tuvo por objetivos: (1) explorar a través de la creación de retratos-collages los procesos de subjetivización masculina en contexto penitenciario, (2) dialogar en el proceso de creación de retrato-collages sobre las experiencias personales que configuran la construcción identitaria y (3) repensar desde los retrato-collages los sentidos y narrativas asociadas a una masculinidad vivida con hombres privados de libertad. Este estudio se posicionó desde una mirada construccionista-social, incorporando estrategias de investigación educativa basada en las artes y los estudios de las masculinidades para abordar con las posibilidades narrativas y representacionales del retrato-collage, los procesos de subjetivización y construcción de identidades masculinas en contexto de reclusión penitenciaria. Desde una mirada crítica, se analizan las tensiones entre visibilidad e invisibilidad en la construcción de los retratos-collages, proponiendo cuestionamientos sobre lo que se vuelve visible y lo que se invisibiliza, la presencia y la ausencia, y otros dualismos que se desbordan para cruzar los límites entre lo que sé es y lo que sé deja de ser. En el proceso de indagación se develaron una serie de inquietudes representacionales, donde la exploración, la experimentación y la yuxtaposición de imágenes reaparece como estrategia visual que re-configura la creación de autorretratos. En éstos, los elementos compositivos se conjugan para ofrecer rostros de múltiples caras, inexactos e inciertos, pero prevenidos para dialogar con la mirada de los otros. Relaciones de intercambio en un entorno aislado pero complejo y diverso en cuanto culturas, credos, procedencias y edades. Retratos-collages que devienen en rostros para ser releídos como los auténticos mapas de la complejidad identitaria individual, experiencias subjetivas enmarañadas en vivencias personales asociadas a una temporalidad narrativa que vuelve a un pasado errado, un presente condicionado y un futuro anhelado que no renuncia a la impronta hegemónica.

ABSTRACT

This poster gives an account of the process and scope of an inquiry that had as its objectives: (1) to explore through the creation of portrait-collages the processes of masculine subjectivization in a penitentiary context, (2) to dialogue in the process of creating portrait-collages on the personal experiences that make up the construction of identity and (3) to rethink from the portrait-collages the senses and narratives associated with a masculinity lived with men deprived of freedom. This study was positioned from a constructionist-social perspective, incorporating educational research strategies based on the arts and studies of masculinities in order to deal with the narrative and representational possibilities of the portrait-collage, the processes of subjectivization and construction of masculine identities in the context of penitentiary imprisonment. From a critical point of view, the tensions between visibility and invisibility in the construction of portrait-collages are analyzed, proposing questions about what becomes visible and what becomes invisible, presence and absence, and other dualisms that overflow to cross the limits between what I know is and what I know ceases to be. In the process of investigation a series of representational concerns were revealed, where the exploration, experimentation and juxtaposition of images reappears as a visual strategy that re-configures the creation of self-portraits. In these, compositional elements are conjugated to offer faces of multiple faces, inaccurate and uncertain, but prevented to dialogue with the gaze of others. Relationships of exchange in an isolated but complex and diverse environment in terms of cultures, creeds, origins and ages. Portraits- 
collages that become faces to be reread as the authentic maps of individual identity complexity, subjective experiences entangled in personal experiences associated with a narrative temporality that returns to an erroneous past, a conditioned present and a desired future that does not renounce the hegemonic imprint.

\section{INTRODUCCIÓN}

En el marco de una invitación por parte de un funcionario del área de mediación del Centro Penitenciario Cuatro Caminos (Granollers), se gestó una iniciativa para la realización de un taller en torno a masculinidades dirigido a los internos del Módulo $\mathrm{N}^{\circ} 6$ de delitos de violencia sexual. Tomando en consideración algunas orientaciones de experiencias de mediación artística y pedagogía crítica (Rodrigo, 2015) el taller se concibió como una oportunidad para indagar y abordar cuestiones en torno a los procesos de subjetivización e identidad masculina, posibilitando dinámicas de acción que no se adscribiesen a un ejercicio de manualidad, terapia o intervención, sino que se concibiera como una experiencia que permitiera abrir un diálogo horizontal para narrarnos y repensarnos a través de la creación de retrato-collages. Cada taller se abrió como un camino alternativo en el que se movieron y pusieron en relación otras matizaciones del aprehender, para ir avanzando más allá de los aspectos del mundo de afuera y considerar la relevancia de los objetos y hechos que se pueden crear y experimentar (Hernández, 2006) para compartir, colaborar y dialogar, resignificando el aula carcelaria como espacio social (Sisto, 2008) que permiten construir y co-construir identidad.

\section{METODOLOGÍA}

La investigación emerge de un estudio de caso, el cual se llevó a cabo desde un posicionamiento construccionista-social de la investigación. Bajo esta perspectiva, se concibe la realidad en términos de los significados construidos y reconstruidos por los participantes en base a sus experiencias y su contexto particular (Ibáñez, 2001), lo que también implica considerar las trayectorias de quienes nos vemos involucrados y participamos del taller, pero asimismo, convertir la actividad de indagación en una experiencia personalmente significativa y de aprendizaje contextualizado (Domingo \& Hernández, 2015). A su vez, se recogieron las virtudes de la Investigación Educativa Basada en las Artes, ese conjunto de estrategias y métodos propios de la creación artística, igualmente pertinentes para la realización de una investigación (Eisner y Barone, 2006). Se consideró al collage como el detonante creativo que movilizara todo el proceso de investigación. De lo anterior, la experiencia personal y colectiva, se articularon como interacciones significativas (Denzin \& Lincoln, 2005) que permitieron explorar, participar y comprender la experiencia desde su singularidad (Grupo L.A.C.E., 2013), considerando en ello que el lenguaje, el ser humano y la materia no son entidades separadas, sino que están mezcladas e imbricadas entre sí (Lather y St. Pierre, 2013). A continuación, esbozo un marco referencial sobre las tensiones entre visibilidad e invisibilidad para situar el proceso creativo y las narrativas en torno a la construcción de retrato-collages por parte de los internos y, finalmente, concluir y exponer los resultados del presente estudio.

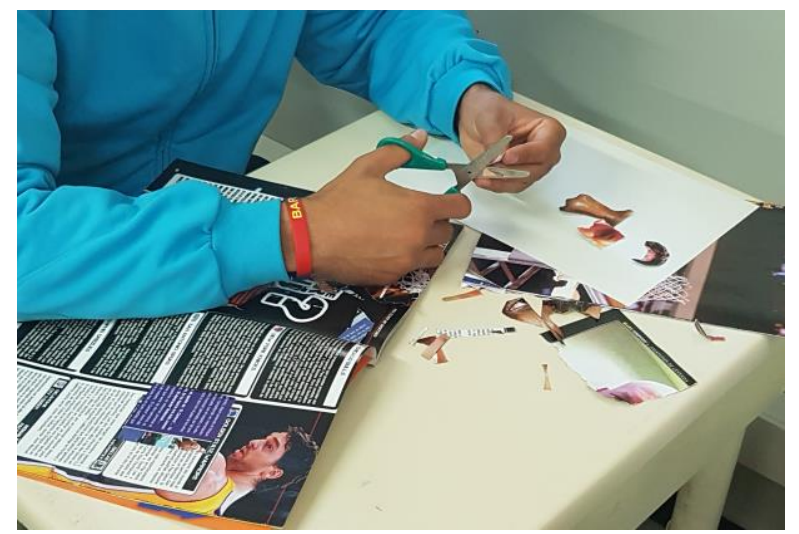

Figura 1. Proceso de creación de un retrato-collage.

\section{DESARROLLO}

Se extendió una invitación abierta a todos los internos del Módulo ํ6 para participar en un taller de collage. Por las limitaciones espaciales del aula del módulo penitenciario, se consensuaron dos grupos de trabajo. Asimismo, se definieron dos sesiones semanales 
de tres horas de taller por cada grupo. En las primeras sesiones se realizó una acotada explicación sobre el collage, para lo cual se consideró pertinente no llevar ejemplos visuales, sino remitir a las posibilidades creativas, compositivas y discursivas de las imágenes para indagar[nos]. Previo consentimiento de los participantes, conseguí grabar el audio de las conversaciones y fotografiar el proceso de creación de los retrato-collages y la presentación de los mismos, pero en ningún caso, fotografiarlos a ellos.

Con revistas en mano y con la posibilidad de articular imágenes, cada uno de los presentes, incluyéndome, comenzamos a elaborar un collage en torno a la pregunta: ¿Qué significa ser hombre? En la segunda y última sesión realizamos un [auto]retrato-collage que respondiera individualmente a otra interrogante: ¿Cómo me identifico? En todas las sesiones se abrieron espacios de diálogo para compartir experiencias sobre el trabajo realizado. Cabe destacar los alcances de una dinámica de acción centrada en las relaciones (Gergen, 2007) reconociendo y valorando los espacios de diálogo para compartir sobre las miradas proyectadas en los modos de representación y las propias prácticas sociales. Como señala Rancière (2010) "comenzar a construir otras realidades, otras formas de sentido común, es decir, otras disposiciones espacio-temporales, otras comunidades de palabras y cosas, de formas y de significaciones" (p.104).

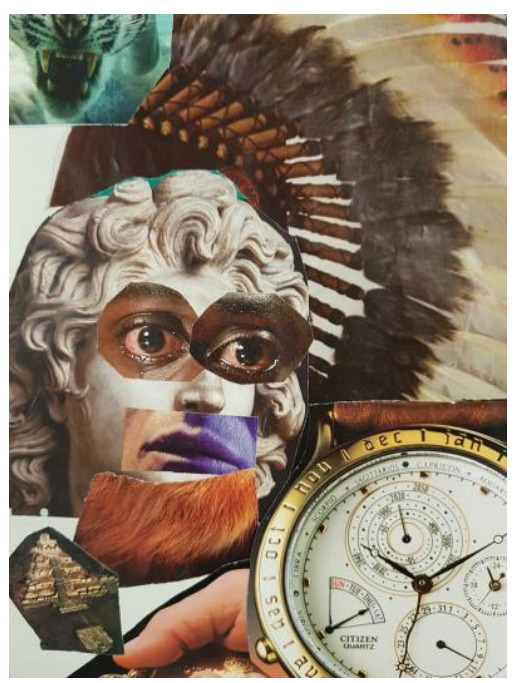

Figura 2. Retrato-Collage de un participante.

\section{Tensiones entre Visibilidad e Invisibilidad}

Al releer las narrativas orales transcritas asociadas a cada uno de los retro-collages, emerge "ese juego complejo de relaciones entre lo visible y lo invisible, lo visible y la palabra, o dicho y no lo dicho" (Rancière, 2010, p.98), contenidas en el deseo como modo de producción y construcción de algo (Guattari y Rolkin, 2005). Narrativas que emergen en torno a nuestras acciones y toma de decisiones, permitiéndonos volver a zonas grises, esas definiciones socio-históricas que nos subyugan y restringen nuestras narraciones de lo que significa "recrear y vivir ser hombre" (Cortés, 2004, p.45). Los retrato-collages se presentan como mediadores identitarios, de tal manera que ya no se puede separar la visión de cuestiones históricas más amplias sobre la construcción de la subjetividad (Crary, 2003), desde aquí, podemos comenzar a hablar de

“...armar una historia acerca de si mismo, recordar el pasado, entretejer los acontecimientos o, mejor, los deseos... con sucesos ulteriores, tratar de entender a través de medios narrativos lo que ha sido su vida, los callejones sin salida con que tropieza una y otra vez y lo que podría aún llegar a ser" (Butler, 2009, p.75)

Lo visible conecta con narrativas relacionadas a prácticas sociales que configuran identidades entrelazadas a argumentos instituidos en el contexto penitenciario, proyectando un futuro alineado al rol de un hombre responsable, correcto, padre, esposo, trabajador. Deseos que, desde lo invisible, vuelven a un modelo social hegemónico que impone un modo particular de "configuración de la subietividad, la corporalidad, la posición existencial del común de los hombres y de los hombres comunes, e inhibe y anula la jerarquización social de las otras masculinidades" (Bonino, 2003:7).

Lo visible también es la cara de las formas hegemónicas de identidad que se presentan como modelos estereotipados y expulsan cualquier otra experiencia que dé cuenta de alguna debilidad. Es así como lo invisible conecta con el pasado culposo y errado, pero también con la fragilidad que se oculta a los otros. Las masculinidades, más allá de una construcción sociocultural, son también reproducción y producto de la interacción social fundada a partir de determinadas estrategias, recursos y discursos de representación. 
Los diferentes tipos de masculinidad no derivan de situaciones o estados homogéneos e inalterables, sino que proceden de la contradicción provocando tensiones entre deseos y prácticas (Cabello y García, 2011:83).

Los retrato-collages se articulan como imágenes que entrelazan el lenguaje y las experiencias, ese lugar de apariencias, pero también de indeterminaciones que re-configuran la producción y reproducción de subjetividades. Desde aquí es posible realizar un examen de las subjetividades masculinas más allá de las categorizaciones que buscan distinguir diferencias o similitudes reproducidas y organizadas jerárquicamente. El proceso de creación de los retrato-collages posibilita detonar narrativas orales y visuales en torno a los flujos, circulaciones y tránsitos que configuran la producción de subjetividades masculinas en el contexto penitenciario. Pero también, posibilita abrir cuestionamientos para [auto]interrogarnos y explorar esos espacios donde coexisten narraciones hegemónicas que suelen "ocultar las relaciones entre los cuerpos, los pequeños gestos, lo que ocurre en el fuera de campo, los vacíos, las posiciones silenciadas" (Hernández, 2013. p.85) entrecruzando cuestiones sociales, políticas y éticas en la re-configuración y representación de identidades, esas derivas propias de los procesos de subjetivización.

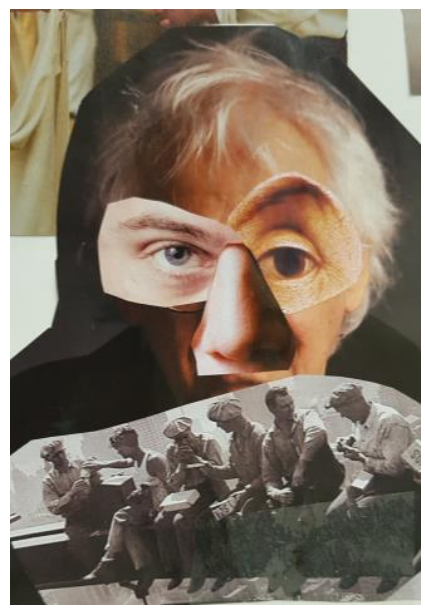

Figura 3. Retrato-Collage de un participante.

\section{CONCLUSIONES}

Las conclusiones de este estudio de caso emanan de las narrativas, los agenciamientos y las experiencias compartidas en el taller donde se llevó a cabo la creación de los retrato-collages. Experiencias de un taller realizado en un centro penitenciario que propició la apertura de espacios de diálogo para interrogarnos sobre los devenires de nuestra identidad y los procesos de subjetivización masculina. En el proceso de creación convergieron las historias vividas, el encuentro de los cuerpos, rostros y miradas, nuestros devenires y nuestras existencias. Desde aquí, los retrato-collages se pueden releer como un mapa que habla de nosotros. "El rostro es una superficie: rasgos, líneas, arrugas, rostros alargados, cuadrado, triangular, el rostro es un mapa (...)" (Deleuze y Guattari, 1995:176).

Lo importante de esta indagación es hacer notar que el retrato-collage es una construcción visual, material y simbólica que se desplaza y expande para poder [re]pensarnos desde lo que somos y así interrogar nuestra identidad masculina y las construcciones hegemónicas que operan sobre nuestra subjetividad. De lo anterior, la creación de retrato-collages expuso las tensiones entre visibilidad e invisibilidad adscrita al dominio configurador de la hegemonía. Los participantes del taller crearon una imagen que emerge desde la [auto]identificación y hace alusión a una subjetividad masculinidad que expone, proyecta y hace visible los estereotipos de una masculinidad ideal y de corte patriarcal que pronuncia la heteronormatividad y el indudable rol de un esposo padre de familia trabajador y proveedor. No obstante, esa misma imagen es la que hace invisible una masculinidad que, sin delegar de la imagen hegemónica, es necesaria para encubrir la fragilidad ceñida al contexto penitenciario. Es la cárcel un espacio cohabitado y posibilitador de procesos socializadores e identitarios (Auge, 1992:46) en el que prevalece una construcción identitaria alineada a los mecanismos de resguardo y los códigos de supervivencia desplegados y exteriorizados frente a otros internos exponiendo enfáticamente la fuerza física, la gravedad, la virilidad, el carácter tosco y la firmeza inquebrantable.

Los retratos-collages son una imagen de [auto]identificación siempre tensionada en aquello que se hace visible pero que también deviene en lo invisible. En su creación se recurrió a imágenes de un amplio abanico visual y representacional que expone y modula estereotipos, metáforas y simbolismos que se re-articulan en la emergencia de la necesidad de construir y reconstruir significados alineados a un discurso de identidad condicionado por los procesos de subjetivización en el contexto penitenciario. Por lo tanto, no deberíamos de dejar de interrogar las formas y modos en los que hoy se construye la hegemonía masculina, las contradicciones que la flanquean, el imaginario visual que las atraviesa y las proyecciones que se perpetúan. 
La creación de los retrato-collages posibilitó la creación de una imagen 'otra', instalándose en el contexto penitenciario, no tan solo para volver a nuestros rostros, sino para releer críticamente las narrativas y discursos sobre lo que significa ser hombre, el lugar de la hegemonía, las pretensiones del contexto, las exigencias sociales y las proyecciones venideras fuera y dentro de la cárcel.

\section{FUENTES REFERENCIALES}

Augé, M. (1992). Los no lugares: espacios del anonimato. Barcelona: Gedisa.

Bonino, L. (2003). Masculinidad hegemónica e identidad masculina. Dossiers feministes, 6, 7-36.

Butler, J. (2009). Dar cuenta de sí mismo. Violencia ética y responsabilidad. Buenos Aires: Amorrout.

Cabello, A. y García, A. (2011). Construyendo la masculinidad: fútbol, violencia e identidad. RIPS, 10(2), 73-95.

Cortés. J. (2004) Hombres de mármol. Barcelona: Egales.

Crary, J. (2003). Cuestionario sobre Cultura Visual. Visuales 1, 82-125.

Deleuze, G. y Guattari, F. (1995). Mil mesetas. Capitalismo y esquizofrenia. Valencia: Pre-Textos.

Denzin, N. y Lincoln, Y. (2005). The Sage Handbook of Qualitative Research. London: Sage.

Domingo, M. y Hernández, F. (2015) Jóvenes que investigan en educación secundaria alternativas para aprender. Revista de Curriculum y Formación del Profesorado, 2(19), 133- 146.

Eisner, W. y Barone, T. (2006). Arts-Based Educational Research. En: J. L. Green, G. Camilli y P. B. Elmore (Eds.), Handbook of complementary methods in education research (pp. 95-109). Mahwah: AERA.

Gergen, K. (2007). Construccionismo social aportes para el debate y la práctica. Bogota: Ediciones Uniandes.

Grupo L.A.C.E. (2013). Los estudios de caso. Barcelona: Depósito digital Universidad de Barcelona.

Guattari, F. y Rolkin, S. (2005). Micropolítica. Cartografías del deseo. Madrid: Traficante de Sueños.

Hernández, F. (2013). La cultura visual en los procesos de documentación sobre cómo los jóvenes aprenden dentro y fuera de la escuela secundaria. VISUALIDADES, Goiânia, 11(2), 73-91.

Hernández, F. (2006). Campos, temas y metodologías para la investigación relacionada con las artes. En: Hernández, F., Muntané, M. y Pérez, H. (Coords.) Bases para un debate sobre investigación artística (p.9-50). Madrid: Secretaría General Técnica Subdirección General de Información y Publicaciones Ministerio de Educación y Ciencia.

Ibáñez, T. (2001). Municiones para disidentes: Realidad, verdad, política. Barcelona: Gedisa.

Lather, P. y St. Pierre, E. (2013). Post-qualitative research. International Journal of Qualitative Studies in Education, 26(6), 629-633.

Rancière, J. (2010). El espectador emancipado. Castellón: Ellego.

Rodrigo-Montero, J. (2015). Kunstcoop: Experiencias de mediación artística en Alemania/Kunstcoop: experiences of art mediation in Germany. Arte, individuo y sociedad, 27(3), 373-392.

Sisto, V. (2008) La investigación como aventura de producción dialógica: La relación con el otro y los criterios de validación en la metodología cualitativa contemporánea. Psicoperspectivas, VII, 114-136. 